\title{
Practice of Controlled Temperature Chain (CTC) Technique during a Mass Vaccination Campaign in Côte d'Ivoire
}

\author{
Damus Paquin Kouassi1 ${ }^{*}$, Lépri Bernadin Nicaise Aka², Bi Vroh Joseph Bénié1, \\ Soplé Ruth Coulibaly ${ }^{2}$, Dodji Blaise Tagodé ${ }^{3}$, Daouda Coulibaly ${ }^{1}$, Kouadio Félix Koffi ${ }^{1}$, \\ Patrick Lydon3, Anna-Lea Kahn33, Olivier Ronveaux ${ }^{3}$ \\ ${ }^{1}$ National Institute of Public Hygiene, Abidjan, Côte d'Ivoire \\ ${ }^{2}$ Immunization Programme Coordination Office, Abidjan, Côte d'Ivoire \\ ${ }^{3}$ World Health Organization, Geneva, Switzerland \\ Email: "paquindamus@yahoo.fr
}

Received 1 February 2016; accepted 26 February 2016; published 29 February 2016

Copyright (C) 2016 by authors and Scientific Research Publishing Inc.

This work is licensed under the Creative Commons Attribution International License (CC BY). http://creativecommons.org/licenses/by/4.0/

(c) (i) Open Access

\begin{abstract}
Background: MenAfriVac ${ }^{\mathrm{TM}}$ is the first of the World Health Organization (WHO)'s pre-qualified vaccines to be allowed to mass vaccination campaign at a temperature below or equal to $40^{\circ} \mathrm{C}$ during 4 days. This new vaccination practice has already been used in some African countries. This article described the opinion and use of this new technique by actors on the field, during a mass vaccination campaign in Côte d'Ivoire, in December 2014. Methods: We conducted a crosssectional study on the practice of CTC by actors on the field and their perception on the new practice, during a mass vaccination campaign in 2 of 25 health districts in Côte d'Ivoire, in December 2014. Findings: As results, in Séguéla $98.25 \%$ of respondents expressed a favourable opinion of CTC, citing advantages such as vaccine carriers requiring no ice packs $(29.2 \%)$, financial benefit $(12.28 \%)$ and lighter vaccine carriers $(5.26 \%)$. In Bouna, respondents gave the same advantages in, respectively, $34 \%, 2 \%$ and $8 \%$ of cases. The peak of the total of vials used for immunization sessions reached 376 vials at day one, then dropped to 235 vials at day three and 220 vials at day six. Discussion: Vaccinators found some benefits related to CTC practice, but on the field, they were cautious in using CTC technique.
\end{abstract}

\section{Keywords}

MenAfriVac, Controlled Temperature Chain, Vaccine, Campaign, Africa, Côte d'Ivoire

${ }^{*}$ Corresponding author.

How to cite this paper: Kouassi, D.P., Aka, L.B.N., Bénié, B.V.J., Coulibaly, S.R., Tagodé, D.B., Coulibaly, D., Koffi, K.F., Lydon, P., Kahn, A.-L. and Ronveaux, O. (2016) Practice of Controlled Temperature Chain (CTC) Technique during a Mass Vaccination Campaign in Côte d'Ivoire. World Journal of Vaccines, 6, 16-22. http://dx.doi.org/10.4236/wjv.2016.61003 


\section{Introduction}

In October 2012, the meningococcal A conjugate vaccine MenAfriVac was granted a label variation by the national regulatoryauthority in its country of manufacture and pre-qualified by WHO to allow for its use in a controlled temperature chain (CTC), at temperatures of up to $40^{\circ} \mathrm{C}$ for no more than four days. MenAfriVac ${ }^{\mathrm{TM}}$ is the first of the World Health Organization (WHO) pre-qualified vaccines to be granted such a label variation [1]. This vaccine provides longer-lasting immunity and reduces naso-pharyngeal portage of meningitis $A$, and no statistical significant difference has been found considering adverse events following immunization (AEFI) [2]-[5]. To eradicate meningitis A in the African meningitis belt, this vaccine has been used in mass vaccination campaigns in several countries including Burkina Faso, Chad, Benin, Nigeria and Togo [6]-[8]. From the economic perspective, MenAfriVac ${ }^{\mathrm{TM}}$ provides benefits in terms of time and resources required for the maintenance of an adequate cold chain during immunization campaigns [9] [10]. Vaccination teams, as noted during previous vaccination campaigns, have found this new technique to be advantageous [10]. Many studies have been conducted on the economic aspects, immunogenicity, and perception of immunization stakeholders in regard to CTC. However, no study has yet obtained monitoring data on the CTC practice of vaccinators during a mass vaccination campaign. We conducted a study of this aspect during a vaccination campaign which lasted 10 days and targeted 4,314,015 people aged 1 - 29 years in two health districts in the northern part of Côte d'Ivoire at higher risk of meningitis A epidemics.

\section{Objectives}

The study aimed to describe vaccinators and their supervisors' knowledge on the principles of CTC technique, to demonstrate the manner in which they implemented it during the mass vaccination campaign, and to obtain their opinions of the technique.

\section{Methods}

\subsection{Study Design}

We conducted a cross-sectional study of the perception and the practice of CTC during the vaccination campaign against meningococcal meningitis in two health districts in the northern part of Côte d'Ivoire of 12 - 21 December 2014.

\subsection{Study Settings}

The study took place in two health districts of Côte d’Ivoire: Bouna and Séguéla (Figure 1). These health districts were selected by the national Health authorities for implementation of CTC because of their insufficient capacity for maintaining the cold chain. The health district of Bouna, located in the north-east of Côte d'Ivoire, includes 24 health areas, and in December 2014 had a target population of 188,520 people. The health district of Séguéla, in the north-west, has 28 health areas, and had a target population of 213,080 people. In both health districts, fixed and mobile vaccination strategies were used depending on the population to be reached.

\subsection{Study Population}

The study population consisted of vaccination teams and their supervisors who were responsible for vaccinating the target populations of the selected health districts during the campaign. There were 112 vaccination teams and 15 supervisors for the health district of Bouna and 118 vaccination teams and 17 supervisors for the health district of Séguéla. Each vaccination team consisted of two vaccinators and one or two volunteers. Our study population consisted on only vaccinators and their supervisors; a minimum of 492 persons. Supervisors were nurses or doctors from the health districts. Vaccinators and volunteers were caregivers, males of females, who usually work with the nurses or doctors of the health districts.

\subsection{Data Collection and Analysis}

Data had been collected by two national WHO consultants coming on the field for the vaccination campaign, and also by the districts’ supervisors. WHO consultants questioned both vaccinators and districts supervisors, 


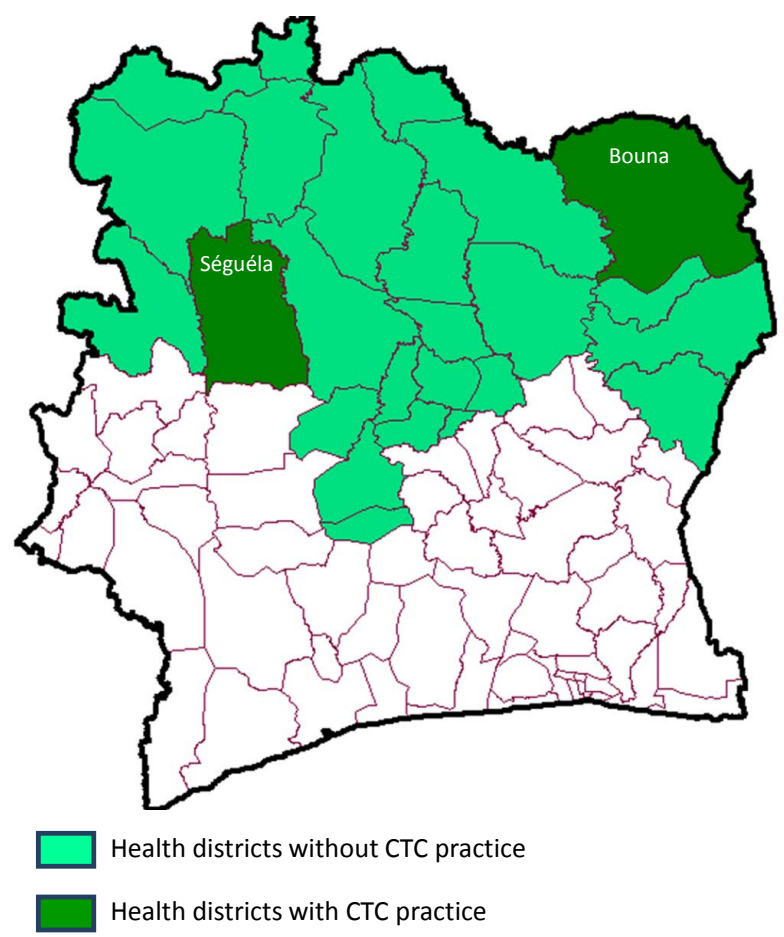

Figure 1. Health districts selected for the meningitis a vaccination campaign in Côte d'Ivoire, in December 2014 (coloured districts indicate areas targeted by the campaign).

and districts' supervisors questioned only vaccinators. Concerning interviewers training for this study, firstly, the WHO national consultants had been trained, in Abidjan, on all the aspects of the vaccination campaign by WHO international consultants. Secondly, both international and national WHO consultants trained districts' supervisors respectively in their districts, before starting the campaign.

We did the interviews during supervisions on the field. We collected two separate sets of data: the first consisted of the results of the interviews with vaccination teams and supervisors concerning their knowledge and perception of CTC; the second consisted of the results of the monitoring of vaccine use.

After obtaining informed consent of the vaccinators and their supervisors, data on their knowledge and perceptions were collected through face-to-face interviews, using a questionnaire designed for this purpose, which contained questions about training in CTC that had taken place before the vaccination campaign, and knowledge and opinions of CTC. The variables were "Duration of CTC training", "Principles of CTC practice", "Opinion on CTC technique", "Benefits related to this technique", "Difficulties related to CTC technique" and "Propositions to improve CTC technique". All the vaccination teams and supervisors met in the field during the supervision period were interviewed: a total of 107 people, 57 in Bouna and 50 in Séguéla.

Monitoring of vaccine use took place through the use of a form, which was designed to be filled out by each vaccination team on each day of the campaign with information on the number and types of vaccine vials with which they were supplied before, during and at the end of every immunization day. Items we considered on the form for this study were, "Number of vials without bar", "Number of vials with 1 bar", "Number of vials with 2 bars", "Number of vials with 3 bars", "Number of vials added during the vaccination session" and "Total number of vials". For every day spent in CTC the vaccine vials were marked with one bar; the number of bars on a vial therefore indicated the number of days spent in CTC [11]. Thus after four days in CTC (as the vaccines could last four days in CTC), a vial could have four bars. At the end of the vaccination campaign, we collected all the forms filled in by the vaccination teams. A total of 151 monitoring forms were collected-112 in Bouna ( $100 \%$ of those expected) and 39 of 118 (33\% of those expected) in Séguéla.

We used Epi Info 3.5.1 and SPSS 17.0 software to enter and analyse data collected from, respectively, the questionnaires and monitoring forms. On the basis of these data, averages and proportions were calculated from both quantitative and qualitative variables. 


\section{Results}

We interviewed 107 over a minimum of 492 vaccination actors, with a participation rate of 21.7\%. Because interviews were done during supervisions and because of time limitation, it was tough to reach some vaccination teams and their supervisors on the fields, especially during mobile strategy.

\subsection{Knowledge and Perception of Vaccinators and Supervisors on CTC Practice}

As regards training, in Seguela $85.96 \%$ and in Bouna $90 \%$ of respondents to the questionnaires claimed to have been trained in CTC practice for between two and four hours. All the respondents in Séguéla and 94\% in Bouna knew that vaccines can last four days in CTC at a temperature of up to $40^{\circ} \mathrm{C}$. In Séguéla, $98.25 \%$ of respondents expressed a favourable opinion of CTC, citing advantages such as vaccine carriers requiring no ice packs (29.2\%), financial benefit (12.28\%) and lighter vaccine carriers (5.26\%). In Bouna, respondents gave the same advantages in, respectively, 34\%, $2 \%$ and $8 \%$ of cases. However, a few respondents explained that the practice of CTC required increased vigilance through the checking of control temperature threshold indicators (3.50\% of respondents in Séguéla and 2\% in Bouna). To improve CTC practice, participants in Séguéla (12.28\%) and in Bouna (2\%) proposed to extend the prescribed time limit of four days (Table 1).

\subsection{Vaccine Monitoring}

Vaccine monitoring data showed a median of $5 \pm 7.5$ vials without bar (i.e. not used the previous day) taken by each vaccinator team for daily immunization sessions. The highest median was at day one (26.5 \pm 30 vials); the median decreased by almost half at day two, then to $14 \pm 20$ vials at day three, to become constant from day four to day seven. For the other kinds of vaccine vials, medians were almost zero (Figure 2). The vials used most during the daily immunization sessions were those with out any bars, except at day six when the maximum was in vials with 1 bar (220 vials). The peak of the total of vials used for immunization sessions reached 376 vials at day one, then dropped to 235 vials at day three and 220 vials at day six (Figure 3). In terms of vials remaining after immunization sessions, the highest number was that of vials without bar, with a peak of 80 vials at day four, except for day five where vials of 1 bar were predominant (50 vials).

\section{Discussion}

The results of our study show caution from vaccinators in practicing CTC, despite their knowledge of the practice and the benefits related to it. Indeed, the predominance of the use of vials without any bars means that the vaccinators tended to finish their daily vaccine allocation and topped up the next day with new vaccine vials (i.e. without bar). If the vaccinators had been practising CTC properly, vials with an increasing numbers of bars should be observed. The under-utilization of CTC in our study could be related to vaccinators' former habits, learnt during immunization campaigns using the cold chain; they chose to be careful about their daily vaccine provision in order not to lose any vaccine vials. In Benin, 15,000 MenAfriVac ${ }^{\mathrm{TM}}$ vaccine vials had been lost because the time limit had been exceeded [12]. The vaccinators in the present study may not, therefore, have been coached enough to practice CTC effectively in the field. Regarding the obvious economic benefits that CTC practice can provide [10], full advantage was taken during this vaccination campaign insofar as commuting and associated costs for supplying vaccines were concerned. During the campaign, vaccinators noted the positive impact of not having to use cold packs on the weight of vaccine carriers.

In order to achieve optimal CTC practice, vaccination coordinators could provide each vaccinator team with sufficient vaccines to cover four days of vaccination using CTC, instead of giving vaccinators the ability to decide on their own the daily quantity and selection of vaccines. If not, practising the benefits of CTC in countries with generally efficient cold chain resources are likely to be marginal [13], as observed in this vaccination campaign.

\section{Study Limitations}

The low response rate could bias our results. Time constraints and vaccination mobile strategy had not allowed us to reach more interviewees who were on the field; we could meet them only on the field during the campaign time period. If an alternative was to meet them altogether in the same place, it would have necessitated extra 
Table 1. Knowledge and perception of vaccination field actors on CTC practice during a mass vaccination campaign using MenAfriVac ${ }^{\mathrm{TM}}$ vaccine, Côte d'Ivoire, 2014.

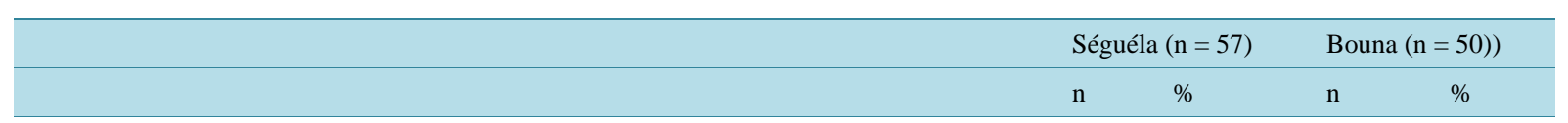

\section{CTC training}

What was the duration (in hours) of your training on CTC?

$\begin{array}{llcc}\text { Mean } & 3 \pm 1.22 & 2.48 \pm 1.035 \\ 1 & 5 & 8.77 & 3 \\ 2-4 & 49 & 85.96 & 45 \\ 5-7 & 90 & 3.51 & 2\end{array}$

\section{Knowledge and practice of CTC}

Do you know the principles of CTC?

Vaccine and solvent storage at a temperature of up to $40^{\circ} \mathrm{C}$ during four days

Checking the vaccine conservation sticker

Removing reconstituted vials after six hours

Storing vaccines and solvents in the shade

$\begin{array}{llll}57 & 100 & 47 & 94 \\ 57 & 100 & 42 & 84 \\ 57 & 100 & 48 & 96 \\ 55 & 96.49 & 48 & 96\end{array}$

3. Opinion on CTC practice

What do you think about this new vaccination practice?

Favourable

$\begin{array}{llll}56 & 98.25 & 45 & 90\end{array}$

What are the benefits?

Vaccination without cold chain

Economic

Time saving

Easy/fast

Light-weight vaccine carriers

Money saving in terms of fuel expenditure for maintaining the cold chain

56.250

What are the difficulties related to CTC practice?

Limited delay

Need for more vigilance from vaccinators to control vaccine quality indicators

$\begin{array}{llll}17 & 29.2 & 14 & 34 \\ 7 & 12.28 & 1 & 2\end{array}$

High risk of vaccines exceeding the time limit of 4 days

$\begin{array}{llll}2 & 3.51 & 1 & 1\end{array}$

$\begin{array}{llll}2 & 3.51 & 1 & 1\end{array}$

$\begin{array}{llll}3 & 5.26 & 2 & 4\end{array}$

$\begin{array}{llll}3 & 5.26 & 4 & 8\end{array}$

$\begin{array}{llll}1 & 1.75 & 1 & 2\end{array}$

What are your propositions to improve CTC practice?

Increase the prescribed time limit of 4 days

$\begin{array}{llll}7 & 12.28 & 1 & 2\end{array}$

time, extra logistics and extra financial means. Additionally, we were not able to complete the vaccination campaign micro-plans during preparation phases due to time constraints. Therefore, without knowing a given team's target, we ignored exactly the correct amount of vaccine vials necessary for the team target populations; this could make difficult to assess the accuracy of the vial-marking procedure. However, because of the CTC technique, we expected vaccinators to be supplied by their supervisors in vaccine vials for several days in order to take advantage of this new technique. Vaccinators' teams and their supervisors could have been cautious in vaccine supplying as it was their first experience with CTC technique.

We didn't look for an ethic committee approval before conducting the study, as the questionnaire covered only technical aspects related to field actors' use of the CTC technique and their opinion on it. For this reason, we even didn't collect information on their social and demographic status.

\section{Conclusion}

Though CTC technique can provide a lot of benefits for African countries during vaccination campaigns, its use 
on the field still require more training and time for field's actors to change their former behavior in vaccination cold chain techniques. This study should be replicated in other countries where CTC technique is implemented in order to not have only the opinion of fields' vaccinators but also their real practice of this new technique.

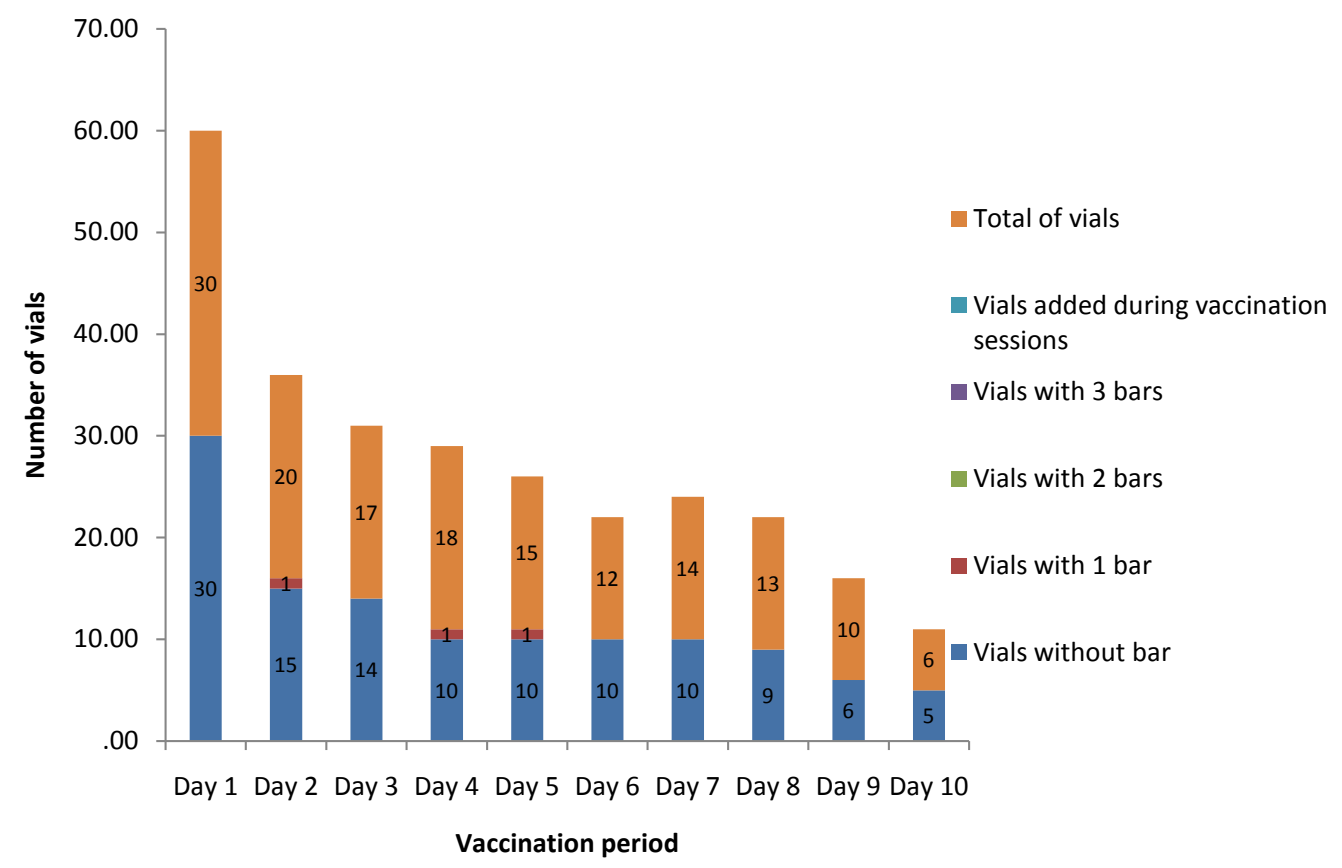

Figure 2. Number of vials used during vaccination sessions, mass vaccination campaign using MenAfriVac $^{\mathrm{TM}}$ vaccine, Côte d'Ivoire, 2014.

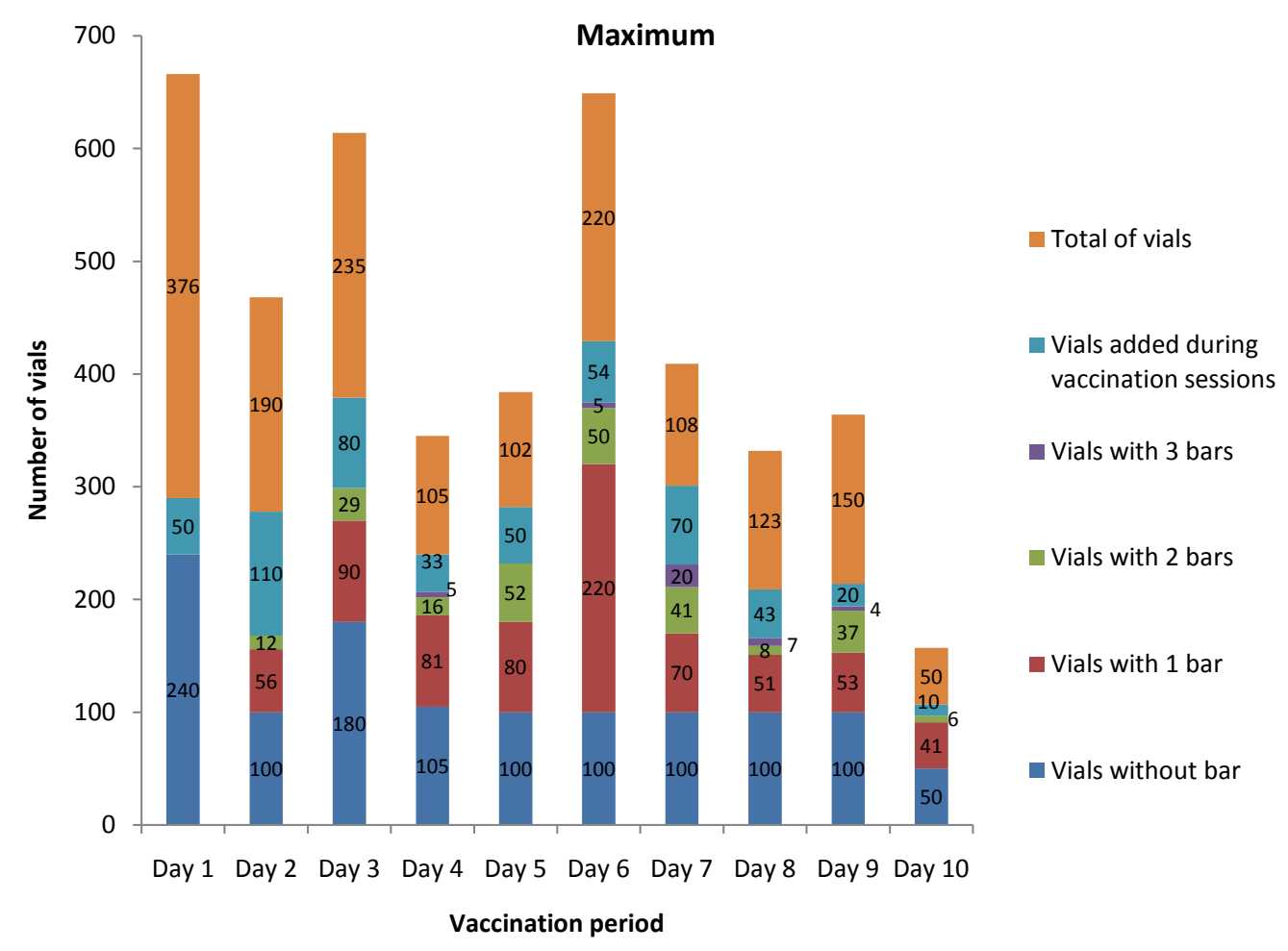

Figure 3. Maximum of the number of vials used during vaccination sessions; mass vaccination campaign using MenAfriVac ${ }^{\mathrm{TM}}$ vaccine, Côte d'Ivoire, 2014. 


\section{Acknowledgements}

We would like to thank the Ivorian Ministry of Health and the Fight against HIV/AIDS, the National Institute of Public Hygiene, the Immunization Programme Coordination Office, the Bouna and Séguéla health district teams, the WHO Côte d'Ivoire Country Office, and Pierre Bwalé (WHO consultant).

\section{Funding}

This vaccination campaign was funded by the Ivorian Government, the Global Alliance for Vaccines and Immunisation (GAVI), and the World Health Organization.

\section{Conflict of Interest}

None.

\section{References}

[1] World Health Organization (2012) Revolutionary Meningitis Vaccine Breaks Another Barrier: First to Gain Approval to Travel Outside Cold Chain. Immunization, Vaccines and Biologicals. http://www.who.int/immunization/newsroom/menafrivac_20121114/en/index.html

[2] Hirve, S., Bavdekar, A., Pandit, A., Juvekar, S., Patil, M., Preziosi, M.P., et al. (2012) Immunogenicity and Safety of a New Meningococcal A Conjugate Vaccine in Indian Children Aged 2 - 10 Years: A Phase II/III Double-Blind Randomized Controlled Trial. Vaccine, 30, 6456-6460. http://dx.doi.org/10.1016/j.vaccine.2012.08.004

[3] Chaibou, M.S., Bako, H., Salisou, L., Yaméogo, T.M., Sambo, M., Kim, S.H., et al. (2012) Monitoring Adverse Events Following Immunization with a New Conjugate Vaccine against Group A Meningococcus in Niger, September 2010. Vaccine, 30, 5229-5234. http://dx.doi.org/10.1016/j.vaccine.2012.06.006

[4] Ouandaogo, C.R., Yaméogo, T.M., Diomandé, F.V., Sawadogo, C., Ouédraogo, B., Ouédraogo-Traoré, R., et al. (2012) Adverse Events Following Immunization during Mass Vaccination Campaigns at First Introduction of a Meningococcal A Conjugate Vaccine in Burkina Faso, 2010. Vaccine, 30, B46-B51. http://dx.doi.org/10.1016/j.vaccine.2011.12.112

[5] Kristiansen, P.A., Ky, B.A., Ouédraogo, A-S., Sanou, I., Ouédraogo, R., Sangaré, L., et al. (2014) Persistent Low Carriage of Serogroup A Neisseria meningitidis Two Years after Mass Vaccination with the Meningococcal Conjugate Vaccine, MenAfriVac. BMC Infectious Diseases, 14, 663. http://dx.doi.org/10.1186/s12879-014-0663-4

[6] Caini, S., Beck, N.S., Yacouba, H., Maiga, I., Chaibou, I., Hinsa, I., et al. (2013) From Agadez to Zinder: Estimating Coverage of the MenAfriVac ${ }^{\mathrm{TM}}$ Conjugate Vaccine against Meningococcal Serogroup A in Niger, September 2010January 2012. Vaccine, 31, 1597-1603. http://dx.doi.org/10.1016/j.vaccine.2013.01.015

[7] Frasch, C.E., Preziosi, M.P. and LaForce, F.M. (2012) Development of a Group A Meningococcal Conjugate Vaccine, MenAfriVac(TM). Human Vaccines \& Immunotherapeutics, 8, 715-724. http://dx.doi.org/10.4161/hv.19619

[8] Djingarey, M.H., Barry, R., Bonkoungou, M., Tiendrebeogo, S., Sebgo, R., Kandolo, D., et al. (2011) Effectively Introducing a New Meningococcal A Conjugate Vaccine in Africa: The Burkina Faso experience. Vaccine, 30, B40-B45. http://dx.doi.org/10.1016/j.vaccine.2011.12.073

[9] Verguet, S., Jassat, W., Bertram, M.Y., Tollman, S.M., Murray, C.J., Jamison, D.T., et al. (2013) Impact of Supplemental Immunisation Activity (SIA) Campaigns on Health Systems: Findings from South Africa. J Epidemiol Community Health, 67, 947-952. http://dx.doi.org/10.1136/jech-2012-202216

[10] Lydon, P., Zipursky, S., Tevi-Benissan, C., Djingarey, M.H., Gbedonou, P., Youssoufe, B.O. et al. (2014) Economic Benefits of Keeping Vaccines at Ambient Temperature during Mass Vaccination: The Case of Meningitis A Vaccine in Chad. Bull World Health Organ, 92, 86-92. http://dx.doi.org/10.2471/BLT.13.123471

[11] World Health Organization (2015) Utilisation du MenAfriVac ${ }^{\mathrm{TM}}$ (vaccin contre la méningite A) en chaîne à température contrôlée (CTC) pendant les campagnes. Guide d'adaptation et Guide du formateur. www.who.int/iris/bitstream/10665/111624/1/WHO_IVB_13.06_fre.pdf

[12] Zipursky, S., Djingarey, M.H., Lodjo, J.C., Olodo, L., Tiendrebeogo, S. and Ronveaux, O. (2014) Benefits of Using Vaccines out of the Cold Chain: Delivering Meningitis A Vaccine in a Controlled Temperature Chain during the Mass Immunization Campaign in Benin. Vaccine, 32, 1431-1435. http://dx.doi.org/10.1016/j.vaccine.2014.01.038

[13] Toboe, D. (2012) Rapport d’appui technique à l'équipe du bureau de la représentation de l’OMS au Tchad pour l'introduction du nouveau vaccin conjugué contre la méningite A (MenAfriVac ${ }^{\mathrm{TM}}$ ). World Health Organization Regional Office for Africa, Brazzaville. 